\title{
The Adaptive COVID-19 Treatment Trial-1 (ACTT-1) in a real-world population: a comparative observational study
}

\author{
Matilde Tejlbo Frost ${ }^{1}$, Espen Jimenez-Solem ${ }^{1,2,3}$, Mikkel Zöllner Ankarfeldt ${ }^{3,4}$, Martin Erik Nyeland', \\ Anne Helms Andreasen ${ }^{4}$ and Tonny Studsgaard Petersen ${ }^{1,2^{*}}$ (1)
}

\section{Background}

The recently published 'Adaptive COVID-19 Treatment Trial' (ACTT-1) showed that remdesivir is a promising treatment option against coronavirus disease 2019 (COVID-19) [1]. Consequently, remdesivir is now being evaluated for implementation in clinical practice worldwide.

Randomized clinical trials (RCTs) are the current golden standard for procuring evidence of a drug's efficacy, but in order to predict effectiveness and safety in daily clinical practice, it is important to complement the results from RCTs with an evaluation of their transferability to a real-world setting.

To bridge the evidentiary gap between clinical research and clinical practice, the U.S. Food and Drug Administration recognizes the need for harnessing 'Real-World Data' and observational methods to generate evidence of effectiveness to support regulatory decisions concerning drugs [2].

\section{Objective}

The aim of the present study was to examine whether the evidence generated in the ACTT-1 could be applied to a real-world population by comparing characteristics of the included patients and their outcomes in order to evaluate

\footnotetext{
*Correspondence: tonny.studsgaard.petersen@regionh.dk

${ }^{1}$ Department of Clinical Pharmacology, Copenhagen University Hospital

Bispebjerg and Frederiksberg Hospital, Bispebjerg Bakke 23, indgang 20

C, 2. sal, 2400 Copenhagen, NV, Denmark

Full list of author information is available at the end of the article
}

the transferability of the trial's outcomes to the patients eligible for remdesivir treatment in clinical practice.

\section{Methods and findings}

Data for the present study were extracted from hospital electronic health records of all patients with a positive severe acute respiratory syndrome coronavirus 2 (SARS$\mathrm{CoV}-2)$ test in the Capital Region of Denmark admitted to a hospital between March 1 and May 5, 2020. Patients' eligibility was assessed using inclusion and exclusion criteria from ACCT-1. Index time for baseline characteristics and start of follow-up was defined as $24 \mathrm{~h}$ after admission or time of first positive SARS-CoV-2 test result, whichever came last based on an assumption that most patients would have been included in the ACCT-1 trial prior to this timepoint. We assessed mortality and time to discharge as a comparable outcome to time to recovery in ACCT-1, during the first 29 days. Indirect standardization was used to weight the cohort to the same eight-point ordinal severity baseline score as the placebo group in the ACTT-1.

We identified 1053 patients admitted with COVID-19. Four hundred and seventy-four patients were ineligible according to inclusion criteria (385 due to mild disease) and exclusion criteria (84 due to severe chronic kidney disease). The remaining 579 patients had complete follow-up. Compared to the placebo group in the ACTT-1, the patients in the present study were older and less obese and fewer required high-flow oxygen, non-invasive ventilation (NIV) or ventilator treatment (Table 1). The overall study population had a shorter duration to discharge and original author(s) and the source, provide a link to the Creative Commons licence, and indicate if changes were made. The images or other third party material in this article are included in the article's Creative Commons licence, unless indicated otherwise in a credit line to the material. If material is not included in the article's Creative Commons licence and your intended use is not permitted by statutory regulation or exceeds the permitted use, you will need to obtain permission directly from the copyright holder. To view a copy of this licence, visit http://creativecommons.org/licenses/by/4.0/. The Creative Commons Public Domain Dedication waiver (http://creativeco mmons.org/publicdomain/zero/1.0/) applies to the data made available in this article, unless otherwise stated in a credit line to the data. 
Table 1 Patient characteristics at baseline and outcomes

\begin{tabular}{|c|c|c|c|}
\hline Characteristics and outcomes & $\begin{array}{l}\text { ACTT-1, placebo group } \\
(n=522)\end{array}$ & $\begin{array}{l}\text { Capital Region of Denmark } \\
(n=579)\end{array}$ & $\begin{array}{l}\text { Capital Region } \\
\text { of Denmark, weighted } \\
(n=579)\end{array}$ \\
\hline Age (mean, standard deviation, years) & $59.2(15.4)$ & $69.0(14.9)$ & $67.1(14.5)$ \\
\hline \multicolumn{4}{|l|}{ Age intervals $(n, \%)$} \\
\hline $18-39$ years & $60(11.5)$ & $22(3.8)$ & $(5.2)$ \\
\hline 40-64 years & $264(50.6)$ & $174(30.1)$ & $(30.8)$ \\
\hline $65+$ years & 198 (37.9) & $383(66.1)$ & $(64.0)$ \\
\hline Male sex $(n, \%)$ & $332(63.6)$ & $329(56.8)$ & $(57.7)$ \\
\hline BMI (mean, standard deviation, $\mathrm{kg} / \mathrm{m}^{2}$ ) & $30.5(7.3)$ & $27.4(6.4)$ & $28.0(6.2)$ \\
\hline \multicolumn{4}{|l|}{ Summary of comorbidities $(n, \%)$} \\
\hline None & $102(22.5)$ & $132(22.8)$ & $(23.1)$ \\
\hline One & $117(25.8)$ & $165(28.5)$ & $(33.7)$ \\
\hline Two or more & $234(51.7)$ & $282(48.7)$ & $(43.3)$ \\
\hline \multicolumn{4}{|l|}{ Coexisting comorbidities $(n, \%)$} \\
\hline Hypertension & $229(49.9)$ & $299(51.6)$ & $(46.0)$ \\
\hline Coronary artery disease & $46(10.0)$ & $92(15.9)$ & $(14.0)$ \\
\hline Congestive heart failure & $23(5.0)$ & $51(8.8)$ & (7.3) \\
\hline Chronic respiratory disease (emphysema) & $4(0.9)$ & $92(15.9)$ & $(16.0)$ \\
\hline Asthma & $47(10.3)$ & $44(7.6)$ & $(8.7)$ \\
\hline Chronic liver disease (chronic hepatitis, cirrhosis) & $9(2.0)$ & $12(2.1)$ & $(1.8)$ \\
\hline Chronic kidney disease & $22(4.8)$ & $11(1.9)$ & $(1.4)$ \\
\hline Diabetes (type 1+2) & $135(29.6)$ & $133(23.0)$ & $(22.9)$ \\
\hline Obesity & $165(36.2)$ & $129(27.7)$ & $(27.9)$ \\
\hline Cancer & $32(7.0)$ & $81(14.0)$ & $(12.8)$ \\
\hline Immune deficiency (acquired or innate) & $36(7.9)$ & $48(8.3)$ & $(9.5)$ \\
\hline \multicolumn{4}{|l|}{ Treatment requirement on hospital admission $(n, \%)^{*}$} \\
\hline Hospitalized, not requiring oxygen & $60(11.9)$ & $141(24.4)$ & $(11.9)$ \\
\hline Hospitalized, requiring oxygen & $199(39.4)$ & $365(63.0)$ & $(39.4)$ \\
\hline Hospitalized, NIV or high-flow oxygen & 99 (19.6) & $50(8.6)$ & $(19.6)$ \\
\hline Hospitalized, mechanical ventilation or ECMO & $147(29.1)$ & $23(4.0)$ & $(29.1)$ \\
\hline \multicolumn{4}{|l|}{ Outcomes, overall } \\
\hline Median time to recovery/discharged alive in days & $15(13-19)$ & $9(7-11)$ & 29 (21-NE) \\
\hline Death day 14, Kaplan-Meier estimate $\%$ & $11.9(9.2-15.4)$ & $21.6(18.2-24.9)$ & $24.6(18.4-30.6)$ \\
\hline
\end{tabular}

*The 17 patients with missing baseline score in ACCT-1 are not included in the denominator

increased mortality compared to the ACTT-1 placebo group (Fig. 1). Adjusting for differences in baseline severity by weighting the study population increased the time to discharge and to a lesser degree mortality. Twenty-two deaths, of 148, occurred after discharge.

\section{Discussion}

Overall, our study shows that patient characteristics and outcomes in the ACTT-1 differ from the present realworld population. The most pronounced differences are a doubled mortality rate and a larger proportion of patients only requiring supplemental oxygen in the Danish realworld cohort. The increased mortality rate is likely due to the cohorts higher age [3].
In the ACTT-1, the most significant reduction in mortality and an increase in recovery rate were reported for the subgroup of patients only requiring supplemental oxygen. Hence, the observed differences with the present cohort may indicate a potentially larger absolute mortality reduction by remdesivir in a real-world population compared to the ACTT-1, assuming the relative mortality reduction observed in the supplemental oxygen subgroup in the ACTT-1 persists.

Due to the observational nature of the present study, results should be interpreted with caution. We believe, however, that the results are an important supplemental tool to better evaluate the possible impact of introducing remdesivir in clinical practice. 

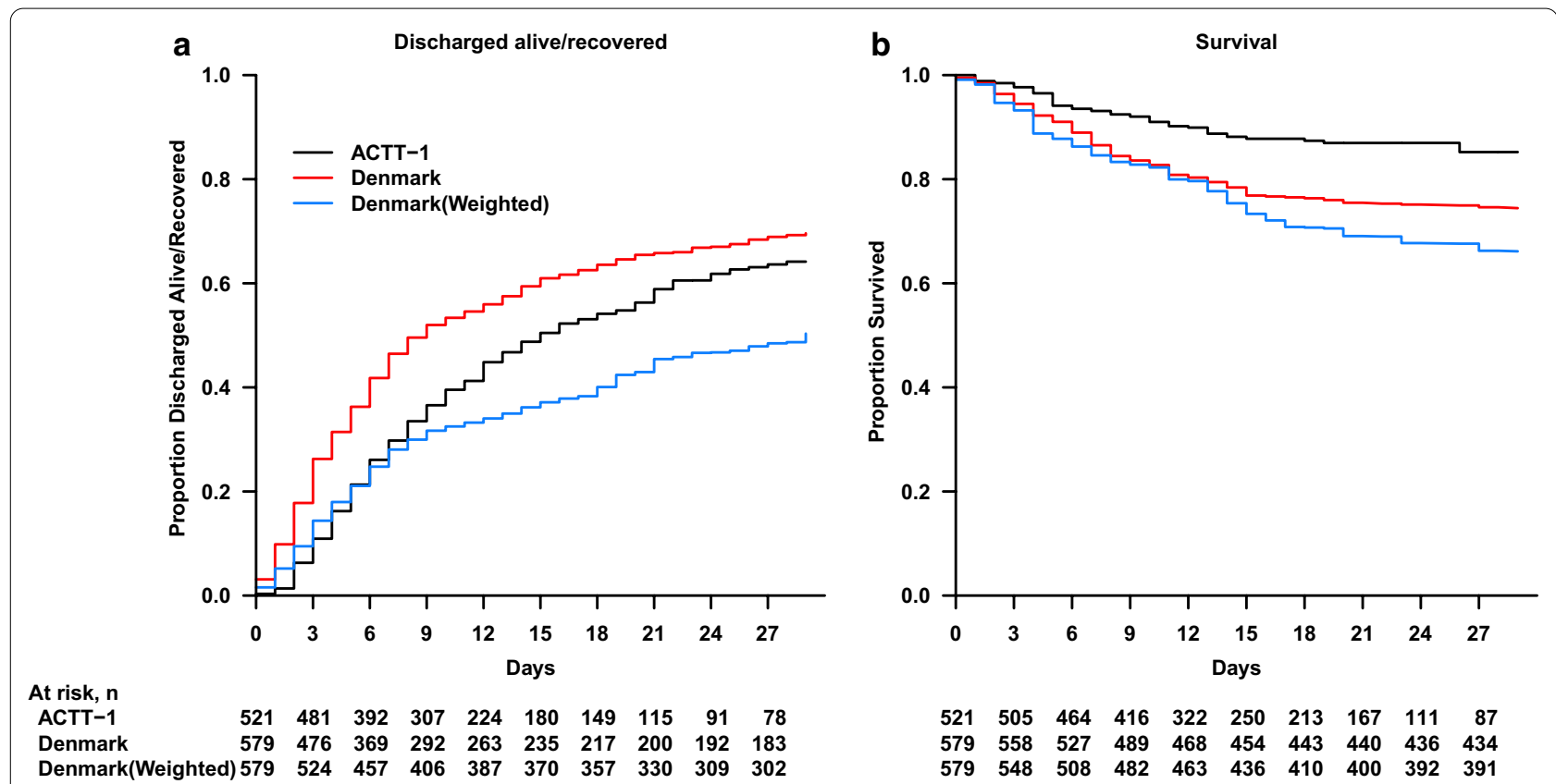

Fig. 1 Kaplan-Meier estimates of cumulative recoveries and mortality by 14 days. Estimates of cumulative recoveries (a) and mortality by 14 days (b) for patients in the Capital Region of Denmark and the placebo group in the ACTT-1 study

\section{Acknowledgements}

The authors would like to thank Gert Mehl Virenfeldt and Janne Petersen from Center for Clinical Research and Prevention, Copenhagen University Hospital Bispebjerg and Frederiksberg for contribution to data management, study design, data interpretation and revising the manuscript.

\section{Authors' contributions}

TSP, EJS and MTF are responsible for the conception. MTF wrote the first manuscript draft. AHA, MEN, MZA and TSP analyzed the data. All the authors did participate in study design, data interpretation and revising the manuscript. All authors read and approved the final manuscript.

\section{Funding}

This study was an investigator-initiated study. It was supported by a research grant from Novo Nordisk Fonden (DK) (NNF20SA0062879).

\section{Availability of data and materials}

The datasets generated and/or analyzed during the current study are not publicly available due Danish law restricting the sharing of non-anonymous personal data.

\section{Ethical approval and consent to participate}

The study was approved by the Danish Patient Safety Authority (31-1521257) and the Danish Data Protection Agency (P-2020-320). Ethics committee approval and informed consent were not required as per Danish law.

\section{Consent for publication}

Not applicable.

\section{Competing interests}

The authors declare that they have no competing interests.

\section{Author details}

1 Department of Clinical Pharmacology, Copenhagen University Hospital, Bispebjerg and Frederiksberg Hospital, Bispebjerg Bakke 23, indgang 20 C,
2. sal, 2400 Copenhagen, NV, Denmark. ${ }^{2}$ Department of Clinical Medicine, University of Copenhagen, Copenhagen, Denmark. ${ }^{3}$ Copenhagen Phase IV Unit (Phase4CPH), Department of Clinical Pharmacology and Center for Clinical Research and Prevention, Copenhagen University Hospital, Bispebjerg and Frederiksberg, Copenhagen, Denmark. ${ }^{4}$ Center for Clinical Research and Prevention, Copenhagen University Hospital, Bispebjerg and Frederiksberg, Copenhagen, Denmark.

Received: 6 September 2020 Accepted: 24 November 2020 Published online: 07 December 2020

\section{References}

1. Beigel JH, Tomashek KM, Dodd LE, Mehta AK, Zingman BS, Kalil AC, et al. Remdesivir for the treatment of Covid-19_-preliminary report. N Engl J Med [Internet]. 22 May 2020 [cited 8 June 2020]. http://www.nejm.org/ doi/10.1056/NEJMoa2007764.

2. https://www.fda.gov/science-research/science-and-research-specialtopics/real-world-evidence.

3. Reilev M, Kristensen KB, Pottegaard A, Lund LC, Hallas J, Ernst MT, et al. Characteristics and predictors of hospitalization and death in the first 11122 cases with a positive RT-PCR test for SARS-CoV-2 in Denmark: a nationwide cohort. Int J Epidemiol [Internet]. 5 Sept 2020 [cited 4 Nov 2020]. https://www.ncbi.nlm.nih.gov/pmc/articles/PMC7499657/.

\section{Publisher's Note}

Springer Nature remains neutral with regard to jurisdictional claims in published maps and institutional affiliations. 